\title{
Advice About Life Plans From Mothers, Fathers, and Siblings in Always-Married and Divorced Families During Late Adolescence
}

\author{
Corinna Jenkins Tucker, ${ }^{1}$ Bonnie L. Barber, ${ }^{2}$ and Jacquelynne S. Eccles ${ }^{3}$ \\ Received October 17, 1997; revised March 4, 2001; accepted June 12, 2001
}

The frequency of advice about life plans that older adolescents in always-married and divorced families received from mothers, fathers, and siblings was examined. Also, a pattern-analytic approach that grouped adolescents according to the amount of advice about life plans received from each parent and a sibling was employed to explore the connections between patterns of advice and adolescents' future occupational, educational, and family plans. The sample included 544 and 95 older adolescents in always-married and divorced families, respectively. Findings suggested that while adolescents relied on mothers for advice in both always-married and divorced families, adolescents in divorced families depended on fathers and siblings for advice less often than did adolescents in alwaysmarried families. Although there was some evidence of family context differences in the connections between patterns of advice and life plans, overall, adolescents

We gratefully acknowledge the assistance of Lisa Colarossi, Andrew Fuligni, Debra Jozefowicz, and Laurie Meschke for their contributions to data collection, coding, and management. We are grateful to Margaret Stone for her comments on an earlier version of this manuscript. This research was supported by grants from the National Science Foundation (DBS9215008) to Barber and Eccles, (92-1459-92) from the William T. Grant Foundation to Eccles and Barber, and by a Spencer Foundation grant to Eccles and Barber.

${ }^{1}$ Assistant Professor, University of New Hampshire. Received PhD in Human Development and Family Studies from The Pennsylvania State University. Major research interests are gender roles, sibling relationships, and adolescent sociocognitive development in always-married, divorced, and dualearner families. To whom correspondence should be addressed at Department of Family Studies, 215 Pettee Hall, The University of New Hampshire, Durham, New Hampshire 03824.

${ }^{2}$ Associate Professor of Family Studies and Human Development, University of Arizona. Received PhD in Developmental Psychology from the University of Michigan in 1990. Research interests include adolescent social relationships across life transitions, and risk, resilience, and prevention in divorced families with adolescents.

${ }^{3}$ McKeachie Collegiate Psychology Professor, The University of Michigan. Received PhD from UCLA in 1974. Most recent work focuses on ethnicity and on the transition from mid-to late adolescence and then into adulthood. 
in both family contexts who received more advice from a parent and, in some cases, a sibling compared to other adolescents were the most positive about their future life plans.

\section{INTRODUCTION}

As part of the identity formation process during late adolescence, youth make decisions about their occupational, familial, and educational plans. It is during this time that adolescents may seek advice from family members with whom they have a long and established relationship and who may hold similar values and can serve as a testing ground for future plans. A limited number of studies indicate that adolescents do discuss life plans with parents (e.g., Barber, 1994; Hunter, 1985; Youniss and Smollar, 1985); however, mothers' versus fathers' roles in adolescents' decision-making process about life plans is relatively unexplored. Also, little is known about siblings' role in adolescents' identity development. Although siblings are less close in adolescence than at earlier ages, adolescent siblings do serve as confidants and sources of advice (Buhrmester, 1992; Tucker et al., 1997). Because adolescence is a time when youth may have difficulty discussing emotionally laden issues with parents, it may be helpful for adolescents to talk with siblings in conjunction with or instead of talking with mothers and fathers about life plans. In addition, at times youth may prefer the reciprocal banter that tends to characterize adolescent sibling relationships (Buhrmester, 1992) when discussing life plans to what may be experienced as more directive and goal-oriented pressures from a parent.

The advice youth receive from parents and siblings about their life plans may be related to nature of their family context. Adolescents in divorced families may be faced with an extra challenge in formulating life plans because, after a divorce, patterns of interaction and family members' relationships and roles change (e.g., Hines, 1997; Kanoy et al., 1984; MacKinnon, 1989). Moreover, nonresidential fathers are less available as sources of advice (Barber, 1994), and mothers may emphasize different life goals for their adolescents because of their divorce experience (Barber and Eccles, 1992). Thus, the amount and content of advice that adolescents receive from parents and siblings regarding life plans may vary across always-married and divorced family contexts. The goals of this study were (1) to describe and compare the extent of advice about life plans older adolescents received from mothers, fathers, and siblings in always-married and divorced families; and (2) to discern meaningful patterns of advice from these family sources that predict adolescents' feelings of confidence about their future plans.

Researchers have hypothesized that there are important connections between the nature of parent-child and sibling relationships. According to social learning theory and as evidenced in some work, there is congruence across family experiences: positivity in parent-child relationships is generally linked to positivity 
in sibling relationship experiences (Brody et al., 1992, 1994; Conger and Conger, 1996; Seigner, 1998). Other work, however, has shown incongruence across family experiences; a sibling may serve as a substitute or compensate for the inadequacies of a parent (Boer et al., 1992; Dunn, 1988; Hetherington, 1988). To date, more empirical advice has been found for the congruence than the compensation pattern. In this study, we explore whether patterns of advice adolescents receive from parents and siblings about life plans are congruent, incongruent, or contingent upon contextual factors.

To explore how patterns of advice from mothers, fathers, and siblings about life plans in always-married and divorced families might be linked to the identity formation process, we employed a pattern-analytic approach (Magnusson, 1988). In contrast to variable-oriented approaches that focus on the relationships between variables, the pattern-analytic approach emphasizes the nature and variability of individuals' experiences. In this study, the pattern-analytic approach highlights the variability across families in the patterns of advice about life plans adolescents receive from parents and siblings. Specifically, we used a pattern-analytic approach that combined the frequency of advice that older adolescents in alwaysmarried or divorced families received from mothers, fathers, and siblings about future plans. These patterns were then used to predict adolescents' certainty and expected success in occupational, educational, and family plans. For each family structure, 4 groups were created reflecting either congruence or incongruence in advice frequency across parent-child and sibling relationships. The congruent groups included adolescents who relied relatively more (Higher parent/Higher sibling) or less (Lower parent/Lower sibling) on both a parent and a sibling for advice about life plans than adolescents in other families. Incongruent groups included adolescents who talked to a parent more and to a sibling less (Higher parent/Lower sibling), or adolescents who received less advice from a parent and more advice from a sibling (Lower parent/Higher sibling) compared to other adolescents.

Previous examinations of congruence and compensation patterns across parent-child and sibling relationships have focused on a single family structure (e.g., always-married or divorced); however, comparison of these patterns across family structures is needed. As noted, family members' relationships and roles change after divorce. Following divorce, noncustodial fathers are less likely than always-married fathers to be a primary target for discussion about school and careers (Barber, 1994; Smollar and Youniss, 1985). Previous research has shown that the importance and nature of children's relationships with noncustodial parents is based less on quantity and more on quality of interaction (Amato, 1993; Amato and Gilbreth, 1999; Emery, 1988). If there is a poor relationship history and/or poor advice from their divorced fathers, adolescents may limit the frequency of interaction with their fathers about future plans. Because fathers are not a frequent resource for advice about life plans in divorced families, adolescents may rely 
more heavily on other family resources. It may be that a compensation pattern (Lower parent/Higher sibling) between father-child and sibling relationships may be more frequent in divorced families than in always-married families. This pattern has been found in other studies of sibling relationship experiences in divorced and disharmonious families (Hetherington, 1988; Jenkins, 1992). A congruent Higher parent/Higher sibling pattern between a parent and sibling in divorced families may also, in some cases, reflect another type of compensation pattern: Adolescents in divorced families may rely more than is typical on their mother and a sibling to compensate for infrequent advice from their father.

In addition to describing links between patterns of congruence or incongruence and family contexts, it is also important to consider whether parents and siblings provide advice that is equally associated with confidence about identity in occupational, educational, and family domains. As suggested by Eccles' expectancy value model (Eccles, 1983), parents make important contributions to the development of their children's expectancies and goals (important components of identity) by conveying their expectancies for their children's future via discussions and advice giving. As such, parents' beliefs about their children's abilities and plans are closely related to their children's expectancies and future plans. Siblings, like parents, may contribute to youth's identity formation process through discussions and advice giving and this may be particularly true for older and more experienced siblings. Perhaps discussions with mothers, fathers, and siblings all help give adolescents confidence in their choices and abilities to achieve their goals. It may be that adolescents who receive relatively more advice about their plans from parents and siblings (a Higher parent/Higher sibling pattern) compared to other adolescents may have the most firm occupational identity and more positive future expectations.

But how important are siblings? Some siblings, particularly those who are younger, may be ill-equipped to offer advice about future adult roles. We might therefore expect a Higher parent/Lower sibling pattern of advice to be linked to more positive attitudes and expectations about future options when compared with Lower parent/Higher sibling and Lower parent/Lower sibling patterns. Although relying on fewer familial resources than adolescents with a Higher parent/Higher sibling pattern, adolescents who have a Higher parent/Lower sibling pattern still have input from a parent (from whom advice about future plans is expected), and therefore they may feel just as confident and positive about their occupational, educational, and family plans as adolescents with the Higher parent/Higher sibling pattern. Alternatively, if siblings make significant contributions over and above those of parents, those adolescents with a Higher parent/Higher sibling pattern would be more advantaged than the Higher parent/Lower sibling adolescents.

Because we expect parental advice to be especially important, Lower parent/ Lower sibling and Lower parent/Higher sibling advice patterns are predicted to be associated with less positive identity development. Specifically, these patterns 
may be related to a weaker occupational identity and a more negative outlook for the future. For both of these advice patterns, adolescents receive or seek little input from a parent - an important and influential familial resource with regard to occupational, educational, family, and life experiences and expectations. Of the 4 advice patterns, adolescents with a Lower parent/Lower sibling pattern may be the most negative about their future life plans because they receive the least amount of family input, and thus feel the least confident and hopeful in their identity formation. Lower parent/Higher sibling adolescents (those who receive less advice than is typical from a parent but more advice than is typical from a sibling) may feel somewhat positive about their future options because they do have a familial resource and, as noted, sometimes it may be helpful for adolescents to talk to a sibling instead of a parent. The Lower parent/Higher sibling pattern may be most beneficial for adolescents who have an older and more experienced sibling who can provide advice similar in nature to a parent's. Because parental advice about future plans is important, however, Lower parent/Higher sibling adolescents may have less positive identity development than adolescents with the Higher parent/Higher sibling or Higher parent/Lower sibling advice patterns.

\section{METHODS}

\section{Participants}

The data are from the 6th wave of the Michigan Study of Adolescent Life Transitions (MSALT), an ongoing longitudinal study of normative and nonnormative transitions during adolescence and young adulthood. These data were collected in 1990 when participants were seniors in high school $(M=18.0$ years, SD $=1.29)$. The demographic characteristics of the sample reflected the 9 predominately white middle- and working class school districts in southeastern Michigan from which the data were collected.

The present study included only adolescents from always-married families and divorced families. The sample was restricted further to adolescents whose siblings were between 13 and 28 years of age because of the domains of life plans being examined (i.e., occupation, education, and family); it is unlikely that adolescents would receive advice about life plans from preadolescent siblings. The final sample included 544 and 95 adolescents from always-married and divorced families, respectively.

\section{Procedures}

At the 6th wave of MSALT, adolescents filled out a questionnaire focused on topics such as the nature of their relationships with parents and siblings, and 
future plans. Questions about the advice adolescents received from their siblings were included only at the 6th wave. Participants were given $90 \mathrm{~min}$ to complete the questionnaire in their school cafeterias with research staff members present to answer questions. Questionnaires and postage-paid return envelopes were mailed to adolescents who had participated in previous waves of data collection but were absent on the day of the survey.

\section{Measures}

Family structure was determined by adolescents' answers to the following question: "Are your biological ('natural') parents: (check one) Married and living together, Divorced, Separated, Never married and living together, Never married and not living together, Widowed?" Those adolescents from divorced families who answered a second question indicating their custodial parent was remarried were excluded from our analyses. Adolescents from remarried families were excluded from the sample even though they have experienced a parental divorce because they have a step parent in the home and a nonresidential parent outside the home. Although the role of stepparents may be important, we did not include questions about step parent advice, and therefore excluded these families from the analyses. The average length of time since the divorce was almost 6 years $(M=5.62, \mathrm{SD}=$ 1.94). The majority of adolescents in divorced families lived with their mothers (79\%).

Advice about life plans from mothers, fathers, and siblings composite variables were created by calculating the mean of 5 Likert-type items about the frequency and helpfulness of talking about future job, education, and family plans with mothers, fathers, and siblings (e.g., "My [mother/father/sibling(s)] and I talk about my future job and educational plans," "Talks with my [mother/father/sibling(s)] have helped me to make family plans"). All of the items had a response scale ranging from 1 (never) to 7 (a lot). The Cronbach's alphas for the composites ranged from 0.88 to 0.94 . The range of the composite variables was from 1 to 7 for adolescents in both family contexts. This composite is similar to a composite used in previous research (Tucker et al., 1997) but 2 items regarding advice about personal problems were dropped because they are less relevant to the identity formation process in educational, work, and family domains.

Future occupational identity was determined by 3 Likert-type 7-point items. After adolescents indicated what job they would like to have when they are 30 years of age, they answered the following 3 questions regarding their occupational choice: "How sure are you that this is the kind of job you would like? How much have you thought about this choice? and How likely do you think it is that you will have this kind of job?" Higher scores reflect greater certainty and more optimism about attaining the hoped-for occupation. The Cronbach's alpha for this scale was 0.77 . 
Expectations for college graduation success were measured by 1 Likert-type item, "When you think about your future how likely do you think the following will be in the next 10-15 years: you will graduate from college?" rated on a 7-point scale. A higher score implies greater expected likelihood of graduating from college.

Expectations for family success included 4 Likert-type items rated on a 7-point scale. Items focused on adolescents' expectations about future marriage and parenting plans. Items were "When you think about your future, how likely do you think each of the following will be: You will get married? You will have a successful, happy marriage? You will have children? You will be a successful parent (raising happy, well-adjusted children)" Higher scores indicate more positive future family expectations. Cronbach's alpha for this measure was 0.85 .

\section{RESULTS \\ Descriptive Analyses of Advice From Mothers, Fathers, and Siblings About Life Plans}

A series of 2 (Adolescent Sex) $\times 2$ (Family Structure) analysis of variance (ANOVAs) examined sex and family structure differences in receiving advice from mothers, fathers, and siblings about life plans. For these and all significant ANOVA results, we calculated effect sizes with the $d$ statistic (Cohen, 1988). A $d$ statistic of 0.20 is a small effect, a $d$ of 0.50 a medium effect, and a $d$ of 0.80 a large effect (Rosnow and Rosenthal, 1989). Females $(M=4.68, \mathrm{SD}=1.65)$ received more advice than males $\operatorname{did}(M=4.11, \mathrm{SD}=1.48)$ from their mothers $(F(1,630)=17.43, p<0.0001 ; d=0.36)$. The same was true for sibling advice $(F(1,635)=11.55, p<0.001 ; d=0.30)$, with females $(M=3.43, \mathrm{SD}=1.71)$ receiving more advice than males $(M=2.96, \mathrm{SD}=1.60)$. In terms of family structure differences, adolescents in always-married families $(M=3.83, \mathrm{SD}=$ 1.50) received more advice about life plans from fathers than did adolescents in divorced families $(M=2.93, \mathrm{SD}=1.61 ; F(3,618)=24.72, p<0.0001$; $d=0.58)$. Further, adolescents in always-married families $(M=3.27, \mathrm{SD}=$ 1.66) received more input about life plans from siblings than did adolescents in divorced families $(M=3.00, \mathrm{SD}=1.77 ; F(1,635)=3.49, p<0.06 ; d=0.16)$. There were no significant interaction effects.

As a basis for creating pattern groups, categorical variables were created for adolescents in each family structure by dividing the composite variables for advice from mothers, fathers, and siblings about life plans at the midpoint (4) of the 7-point scale, with 4-7 designated as "Higher" and less than 4 designated as "Lower." Chisquared analyses were conducted to explore the relative frequency with which adolescents received advice from parents and siblings about life plans in each family 
Table I. Reports of Frequency of Advice From Mothers and Siblings in Always-Married Families $(N=544)$

\begin{tabular}{lcc}
\hline & \multicolumn{2}{c}{ Talk to siblings } \\
\cline { 2 - 3 } Talk to mothers & Higher & Lower \\
\hline Higher & $159(29 \%)$ & $198(37 \%)$ \\
Lower & $50(9 \%)$ & $137(25 \%)$ \\
$\chi^{2}$ & \multicolumn{2}{c}{$16.43^{* * *}$} \\
\hline$* * * p<0.001$. & & \\
\hline
\end{tabular}

structure. For adolescents in always-married families, both chi-squared analyses of advice from mothers and siblings $\left(\chi^{2}(1, N=544)=16.43, p<0.001\right)$ and advice from fathers and siblings $\left(\chi^{2}(1, N=544)=14.22, p<0.001\right)$ were significant. Slightly more adolescents reported congruent (54 and 57\% for Mother/ Sibling and Father/Sibling patterns, respectively) than incongruent (46 and 43\% for Mother/Sibling and Father/Sibling patterns, respectively) advice patterns (see Tables I and II). A Higher mother/Higher sibling pattern was reported $29 \%$ and a Higher father/Higher sibling pattern was reported $24 \%$ of the time by adolescents. Adolescents who received higher amounts of advice from a sibling also were more likely to receive higher amounts of advice from their mothers (76\%) and fathers (63\%). However, adolescents who often discussed future plans with mothers (56\%) and fathers (54\%) were less likely to rely on a sibling. A compensatory pattern (Lower parent/Higher sibling) was uncommon ( 9 and 14\% for mothers and fathers, respectively).

Generally, the chi-squared analyses for always-married families revealed that adolescents were more likely to receive higher than lower levels of advice from mothers and lower than higher amounts of advice from siblings, and about equally likely to receive higher and lower levels of advice from fathers about future plans. The chi-squared analyses of advice from parents and siblings in divorced families were not significant.

Table II. Reports of Frequency of Advice From Fathers and Siblings in Always-Married Families $(N=544)$

\begin{tabular}{lrr}
\hline \multirow{2}{*}{ Talk to father } & \multicolumn{2}{c}{ Talk to siblings } \\
\cline { 2 - 3 } & Higher & Lower \\
\hline Higher & $132(24 \%)$ & $156(29 \%)$ \\
Lower & $77(14 \%)$ & $179(33 \%)$ \\
$\chi^{2}$ & \multicolumn{2}{|c}{$14.22^{* * *}$} \\
\hline$* * *$ & \\
\hline
\end{tabular}




\section{Patterns of Advice From Parents and Siblings About Life Plans}

Two pattern variables were created from the 3 dichotomous variables: (1) frequency of advice from mothers and siblings (Mother/Sibling), and (2) frequency of advice from fathers and siblings (Father/Sibling) for adolescents in each family type. Each variable had 4 levels (i.e., Higher/Higher, Lower/Lower, Higher/Lower, Lower/Higher).

Chi-squared analyses were used to examine differences in adolescents' patterns of advice in always-married and divorced families. There were no family structure differences in Mother/Sibling patterns. In contrast, analyses for the Father/Sibling pattern indicated significant family structure differences in adolescents' patterns of advice about life plans in always-married and divorced families $\left(\chi^{2}(1, N=639)=18.20, p<0.001\right)$. Adolescents in always-married families were more likely to receive a higher level of advice from fathers $(53 \%)$ than adolescents in divorced families (32\%). Also, the Lower/Lower Father/Sibling advice pattern was more common in divorced $(50 \%)$ than in always-married families (30\%). Finally, when adolescents relied on siblings for higher levels of advice, adolescents were more likely to receive lower levels of advice from fathers in divorced (63\%) than in always-married (37\%) families, suggesting that a compensation pattern may be more frequent in divorced than in always-married families (see Table III).

\section{Differences Between Advice Pattern Groups}

We performed analyses to determine how the advice patterns that combined a parent and a sibling were linked to the frequency of advice from the other parent and whether family structure moderated any relations. We explored these connections using a 2 (Family structure) $\times 4$ (Advice pattern) ANOVA for each advice pattern variable (i.e., Mother/Sibling, Father/Sibling) to examine group differences in advice from the other parent. For the Mother/Sibling advice pattern and its links to

Table III. Patterns of Advice From Fathers and Siblings in Always-Married $(N=544)$ and Divorced Families $(N=95)$

\begin{tabular}{lcc}
\hline & Always-married & Divorced \\
\hline Higher/Higher & $132(24 \%)$ & $11(12 \%)$ \\
Lower/Lower & $179(33 \%)$ & $48(50 \%)$ \\
Higher/Lower & $156(29 \%)$ & $17(20 \%)$ \\
Lower/Higher & $77(14 \%)$ & $19(18 \%)$ \\
$\chi^{2}$ & $18.20^{* * *}$ \\
$*_{* * *} p<0.001$. &
\end{tabular}




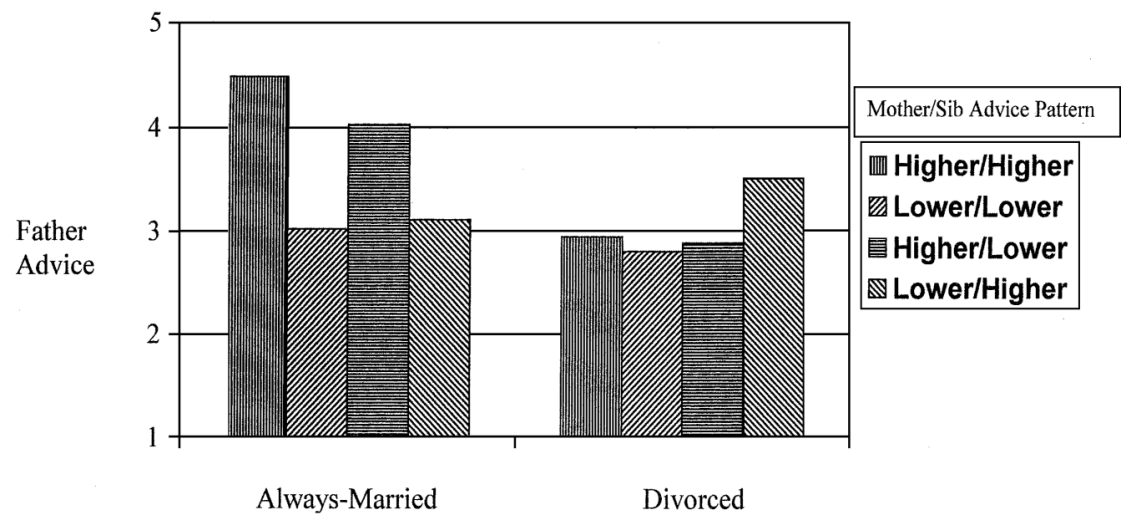

Fig. 1. Father advice by Mother/Sibling advice patterns in always-married and divorced families.

receiving advice from fathers, Family structure $(F(1,614)=10.91, p<0.001)$ and Mother/Sibling advice $(F(3,614)=4.20, p<0.01)$ were significant, and were further qualified by a Family Structure $\times$ Mother/Sibling Pattern interaction $(F(3,614)=4.83, p<0.01)$. Follow-up Least Significant Difference tests indicated that adolescents in always-married families with Higher/Higher and Higher/Lower Mother/Sibling advice patterns talk more frequently with their fathers than adolescents with Lower/Lower $(d=1.11, d=0.75$, respectively) and Lower/Higher $(d=0.96, d=0.64$, respectively) Mother/Sibling patterns. In addition, adolescents with Higher/Higher advice patterns received more advice from their fathers than did adolescents with Higher/Lower advice patterns in always-married families $(d=0.32)$. In divorced families there were no significant differences in advice from fathers about life plans by Mother/Sibling advice pattern (see Fig. 1).

An ANOVA for the frequency of advice from mothers by Father/Sibling advice pattern and family structure revealed a significant Father/Sibling advice effect $(F(3,626)=9.48, p<0.001)$ which was qualified by a Family Structure $\times$ Father/Sibling Pattern interaction effect $(F(3,626)=3.89, p<0.01)$. Adolescents in always-married families with a Higher/Higher Father/Sibling pattern relied on their mothers more than did adolescents in the Lower/Lower $(d=1.11)$, Higher/Lower $(d=0.39)$, and Lower/Higher $(d=0.62)$ groups. Also, adolescents in always-married families with a Higher/Lower Father/Sibling pattern received more frequent advice from mothers than did adolescents with a Lower/ Lower $(d=0.71)$ advice pattern. In divorced families, adolescents with a Lower/ Lower Father/Sibling advice pattern received lower levels of advice from mothers than did adolescents with a Lower/Higher $(d=0.86)$ advice pattern (see Fig. 2).

Next, we explored whether adolescents' advice patterns were significantly associated with their siblings' age using two 2 (Family Structure) $\times 4$ 


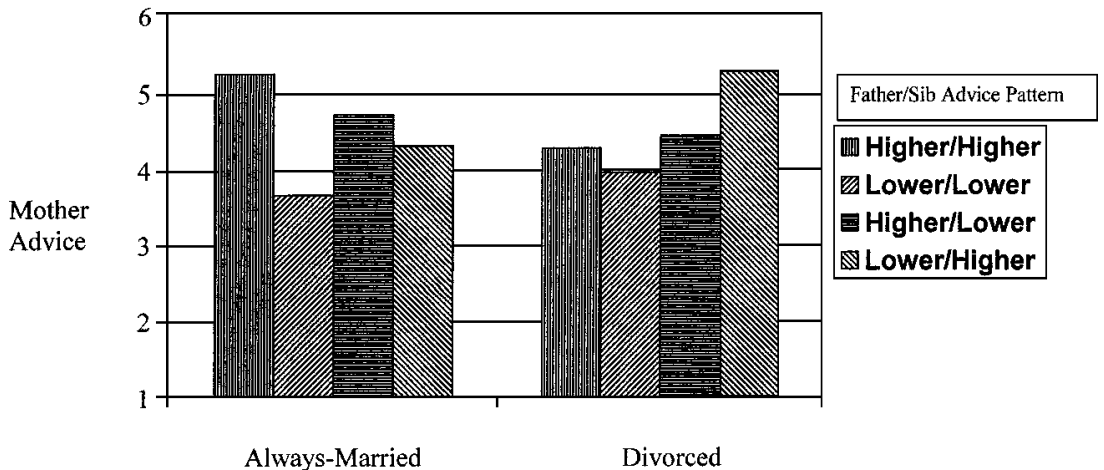

Fig. 2. Mother advice by Father/Sibling advice patterns in always-married and divorced families.

(Advice Pattern) ANOVAs. For both the Mother/Sibling and Father/Sibling advice patterns, adolescents with either Higher/Higher or Lower/Higher patterns had siblings who were older than adolescents with Lower/Lower or Higher/Lower patterns $(F(3,631)=13.07, p<0.001 ; F(3,631)=11.13, p<0.001$; for the Mother/Sibling and Father/Sibling patterns, respectively; see Table IV for means and effect sizes). There were no Family Structure or Family Structure $\times$ Advice Pattern effects.

\section{Advice Patterns and Life Plans}

A series of 2 (Family Structure) $\times 4$ (Advice Pattern) ANOVAs in conjunction with follow-up Least Significant Difference tests was conducted to examine

Table IV. Means (and Standard Deviations) for Adolescents' Parent/Sibling Advice Patterns by Siblings' Ages

\begin{tabular}{|c|c|c|c|}
\hline & \multicolumn{2}{|c|}{ Siblings' age } & \multirow[b]{2}{*}{$d$ statistic } \\
\hline & $M$ & $\mathrm{SD}$ & \\
\hline \multicolumn{4}{|c|}{ Mother/Sibling advice } \\
\hline Higher/Higher & $19.78^{a}$ & 3.07 & $\mathrm{H} / \mathrm{H}$ vs. $\mathrm{L} / \mathrm{L}=0.56$ \\
\hline Lower/Lower & $17.99^{\mathrm{b}}$ & 3.33 & $\mathrm{H} / \mathrm{H}$ vs. $\mathrm{H} / \mathrm{L}=0.73$ \\
\hline Higher/Lower & $17.46^{\mathrm{b}}$ & 3.31 & $\mathrm{~L} / \mathrm{H}$ vs. $\mathrm{L} / \mathrm{L}=0.84$ \\
\hline Lower/Higher & $20.68^{a}$ & 3.31 & $\mathrm{~L} / \mathrm{H}$ vs. $\mathrm{H} / \mathrm{L}=0.97$ \\
\hline \multicolumn{4}{|c|}{ Father/Sibling advice } \\
\hline Higher/Higher & $19.94^{\mathrm{a}}$ & 2.80 & $\mathrm{H} / \mathrm{H}$ vs. $\mathrm{L} / \mathrm{L}=0.65$ \\
\hline Lower/Lower & $17.95^{\mathrm{b}}$ & 3.32 & $\mathrm{H} / \mathrm{H}$ vs. $\mathrm{H} / \mathrm{L}=0.88$ \\
\hline Higher/Lower & $17.31^{\mathrm{b}}$ & 3.32 & $\mathrm{~L} / \mathrm{H}$ vs. $\mathrm{L} / \mathrm{L}=0.64$ \\
\hline Lower/Higher & $20.09^{\mathrm{a}}$ & 3.34 & $\mathrm{~L} / \mathrm{H}$ vs. $\mathrm{H} / \mathrm{L}=0.84$ \\
\hline
\end{tabular}

Note. For each advice pattern, means with different superscripts are significantly different. 


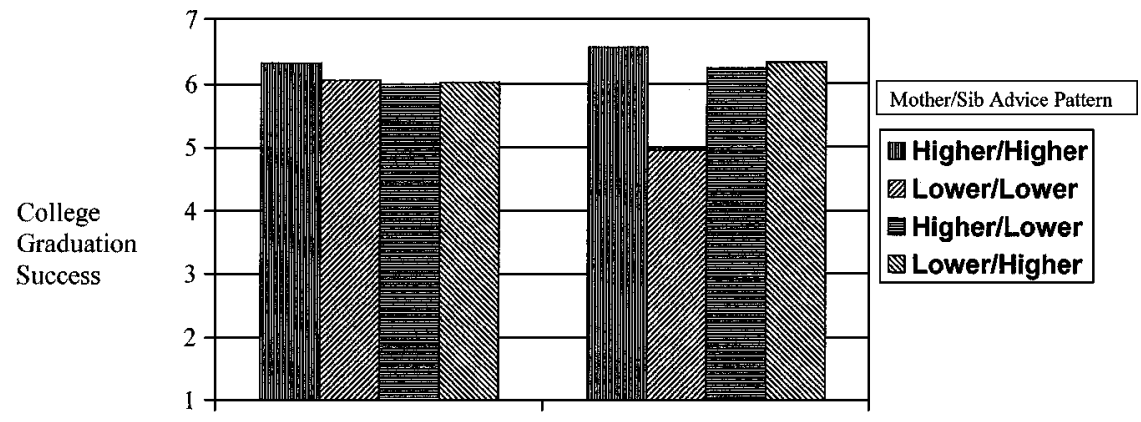

Always-Married

Divorced

Fig. 3. Expectations for college graduation success by Mother/Sibling advice patterns in alwaysmarried and divorced families.

whether various advice patterns were differently associated with confidence about occupational, educational, and family identities and expectations in always-married and divorced family contexts. ${ }^{3}$ The results for the Mother/Sibling pattern are presented first, followed by the results for the Father/Sibling pattern.

\section{Mother/Sibling Advice Patterns and Life Plans}

Beginning with the analysis of future occupational identity, a significant family structure effect revealed that adolescents in divorced families had firmer future occupational identities than did adolescents in always-married families $(F(1,631)=4.99, p<0.03 ; M=2.63, \mathrm{SD}=0.56$ versus $M=2.50, \mathrm{SD}=$ $0.54 ; d=0.24)$. For expectations about college graduation success, a significant Mother/Sibling pattern effect $(F(3,631)=3.99, p<0.01)$ qualified by a Family Structure $\times$ Advice Pattern interaction $(F(3,631)=3.21, p<0.02)$ revealed that adolescents in divorced families with a Lower/Lower Mother/Sibling pattern had lower expectations for college graduation success than did adolescents with a Higher/Higher $(d=0.80)$ or Higher/Lower $(d=0.65)$ pattern. There were no differences in expectations for future educational success in always-married families by Mother/Sibling advice patterns (see Fig. 3).

Finally, analysis for adolescents' expectations for future family success revealed a significant Mother/Sibling pattern effect $(F(3,631)=5.66, p<0.01)$.

\footnotetext{
${ }^{3}$ Additional analyses that included adolescents' sex were conducted due to possible sex differences in nature of parent-child and sibling relationships (Buhrmester, 1992; McHale et al., 1992; Tucker et al., 1997). None of these analyses, however, revealed significant Adolescent Sex $\times$ Family Structure $\times$ Advice Pattern interactions. This may be because some cell sizes for the divorced family subsample were small (e.g., $n=4)$, limiting statistical power. These findings should be replicated on a larger sample of divorced families.
} 
Adolescents with a Higher/Higher Mother/Sibling pattern had the most positive expectations for future family formation as compared to other Mother/Sibling patterns $(M=3.55, \mathrm{SD}=0.64$ versus $M=3.11, \mathrm{SD}=0.85 ; M=3.16, \mathrm{SD}=$ $1.00 ; M=3.35, \mathrm{SD}=0.75$, for adolescents with a Higher/Higher versus Lower/ Lower $(d=0.59)$, Lower/Higher $(d=0.48)$, and Higher/Lower $(d=0.29)$ pattern, respectively). In addition, adolescents with a Higher/Lower Mother/Sibling pattern had higher expectations about their future family plans than adolescents with a Lower/Lower Mother/Sibling pattern $(d=0.30)$.

\section{Father/Sibling Advice Patterns and Life Plans}

Future occupational identity analyses indicated a significant Family Structure $\times$ Advice Pattern interaction effect, $F(1,631)=3.57, p<0.01$. Adolescents in always-married families with a Lower/Lower Father/Sibling pattern were less firm in their future occupational identities than adolescents with a Higher/Higher $(d=0.42)$ or Higher/Lower $(d=0.25)$ Father/Sibling pattern (see Fig. 4$)$. For divorced families there were no significant differences in adolescents' future occupational identities by Father/Sibling advice pattern. A Father/Sibling pattern effect emerged for adolescents expectations for future college graduation success, $F(3,631)=4.25, p<0.01$. Adolescents with either a Higher/Higher or Higher/Lower pattern had higher expectations for college graduation success than did adolescents with a Lower/Lower pattern $(M=6.38, \mathrm{SD}=1.57 ; M=$ $6.20, \mathrm{SD}=1.71$ versus $M=5.75, \mathrm{SD}=2.01 ; d=0.35, d=0.24$, respectively). Finally, analysis of expectations for future family success revealed a significant Father/Sibling $(F(3,631)=4.14, p<0.01)$ pattern effect. Adolescents with a Higher/Higher pattern had more positive family expectations than did adolescents

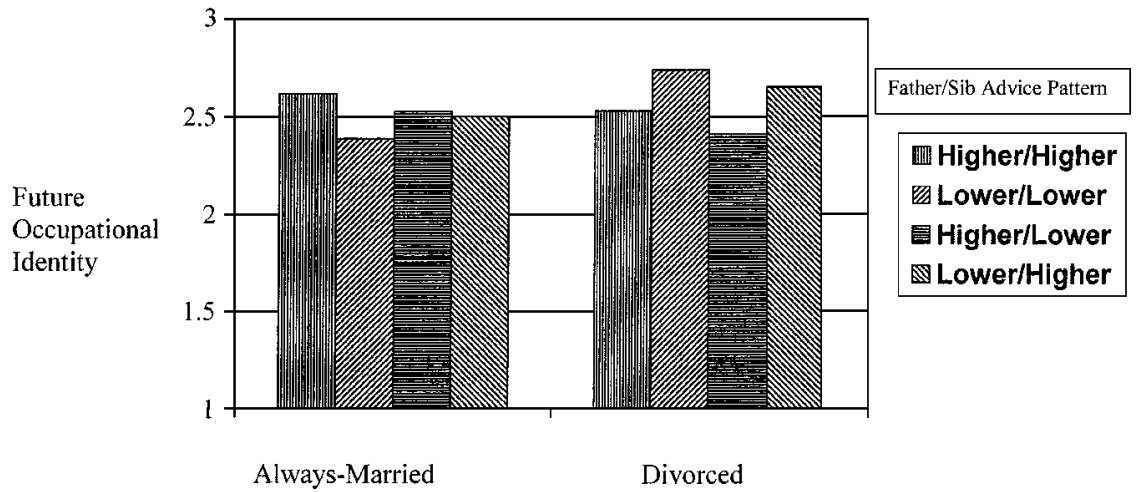

Fig. 4. Future occupational identity by Father/Sibling advice patterns in always-married and divorced families. 
with a Lower/Lower pattern $(M=3.53, \mathrm{SD}=0.64$ versus $M=3.18, \mathrm{SD}=0.84$, respectively; $d=0.47$ ).

\section{DISCUSSION}

In this study, we examined between-family differences in patterns of advice about life plans adolescents received from parents and siblings in always-married and divorced families, and we explored how these patterns were associated with adolescents' future occupational identity and expectations for future educational and familial success. Findings revealed variability in patterns of advice from mothers, fathers, and siblings, and the nature of this variability differed across always-married and divorced families. In general, adolescents who reported Higher/Higher and sometimes Higher/Lower advice patterns were more positive about their future plans, demonstrating that parents and, in some cases, siblings play an important role in the identity formation process. Each of these points will be addressed below.

To examine the potential variability in adolescents' family experiences with regard to advice about life plans, we adopted a strategy termed by Magnusson (1988) as the "pattern-analytic" approach. Specifically, we examined patterns of advice from mothers, fathers, and siblings about adolescents' life plans. To create the patterns, we employed a grouping strategy that, in the face of losing statistical power, revealed interesting group differences in the patterns. Although inconsistent with the social learning theory, but consistent with previous research, this study provided evidence that both congruent and incongruent patterns can commonly occur in family relationship experiences. This finding suggests that mothers and fathers, and sometimes siblings, have important advice-giving roles as adolescents sort through the challenges of the identity formation process.

Congruent and incongruent patterns were about equally evident in both always-married and divorced family structures. There was, however, variability in the frequency with which each type of congruent (i.e., Higher/Higher, Lower/Lower) and incongruent (i.e., Higher/Lower, Lower/Higher) pattern was reported in the two family structures of interest. In other words, the extent to which adolescents relied on their parents and siblings for advice about future plans varied across always-married and divorced families. While mothers played a significant role in giving advice to adolescents about future plans in both family structures, adolescents relied on fathers and siblings more often in always-married than in divorced families. Further, analyses indicated that a Lower/Lower Father/Sibling pattern was more common in divorced than in always-married families. Extrapolating from other work that has shown that adolescents have poorer relationships with fathers (Amato, 1987; Barber, 1994) and siblings (e.g., Amato, 1987; Anderson and Rice, 1992; Hetherington, 1988; MacKinnon, 1989) in divorced than in always-married families, it may be for these reasons that adolescents 
from divorced families rely less on these family resources for advice about life plans.

Siblings' involvement in adolescents' decisions about life plans sometimes occurred in the context of relatively greater reliance on parents for advice about life plans (i.e., Higher/Higher advice pattern), with some evidence suggesting that this pattern was more common in always-married than in divorced families. Siblings also gave advice when a parent was not the primary target for input about life plans (i.e., Lower/Higher advice pattern), a pattern more common in divorced than in always-married families. Other work (Hetherington, 1988; Jenkins, 1992) has also found an incongruent pattern between parent-child and sibling relationships in divorced families and, in this study, this may be because divorced fathers are infrequent targets for advice about future plans (Barber, 1994; Smollar and Youniss, 1985), with some adolescents compensating for this deficit by relying more heavily on their siblings. Following a divorce, some older siblings assume a parentified role (Weiss, 1979) and serve as an important familial resource for advice about future plans. Future work could include exploring how visitation and custody arrangements of divorced families are connected to Parent/Sibling advice patterns about life plans.

As expected, in general, a positive congruent pattern (i.e., Higher/Higher) and sometimes a Higher/Lower incongruent pattern were associated with more positive future occupational identities and expectations whereas a negative congruent pattern (i.e., Lower/Lower) and a Lower/Higher incongruent pattern were linked to less positive future occupational identities and expectations. Extrapolating from Eccles' model (1983), it may be that advice from parents and siblings about life plans is important for adolescent development. Alternatively, adolescents with the most positive identity development may maximize their familial resources. At least in this sample, we found that adolescents with a Higher/Lower Parent/Sibling advice pattern typically had younger, less experienced siblings and input from them may be less important and/or less useful, and advice from a parent (or from both parents-a Higher Mother/Higher Father/Lower Sibling pattern) is sufficient for successful negotiation of occupational, educational, and familial plans. The links between the advice patterns and adolescents' future plans evident in this study were complex and will need to be replicated. Further, the connection between siblings' advice and adolescents' life plans may be greater in other ethnic groups than what was evident in our primarily White sample. Other work has shown that siblings play a more significant role in each other's development in other cultures and ethnic groups (Burton et al., 1995; Rogoff, 1990; Whiting, 1983).

Youth with a Lower/Lower pattern often were the least positive about their future plans. In addition, we found that adolescents with a Lower/Lower Parent/ Sibling pattern also relied on their other parent for advice infrequently. These findings suggest that there is a group of youth that turn to no one in their family and this may account for these adolescents having the least positive identity development. Although a correlational study, these findings suggest the importance of familial 
input and socialization for adolescents' successful negotiation of occupational, educational, and familial goals. Examination of how patterns of advice seeking over time are linked adolescents' eventual future choices and attainment would be an important next step. For example, adolescents with a Lower/Lower Parent/Sibling pattern may be the least likely of the 4 advice pattern groups to attend and graduate college.

Finally, the Lower/Higher Parent/Sibling pattern was not always distinguishable from the Higher/Higher or Higher/Lower pattern in its link to future plans. This may suggest, as noted, that some siblings, particularly older siblings, assume a primary advice role about life plans (i.e., compensation) and that they provide a sufficient familial resource. Alternatively, adolescents with a Lower/Higher Parent/Sibling pattern may have a Higher/Higher advice pattern with their other parent and a sibling and thus, the Lower/Higher advice pattern may not always be linked with a weaker future occupational identity and lower expectations for educational and familial success.

Differences in future plans between the advice patterns across always-married and divorced families were revealed by two interaction effects. One interaction effect indicated that in always-married families adolescents' future occupational identity confidence differed by Father/Sibling advice pattern: adolescents who frequently talked to their fathers were more firm in their occupational identities than adolescents who infrequently talked to their fathers. Perhaps for adolescents in always-married families the more they talk to their fathers about their career choices, the more confident they become about their future occupational identities. In divorced families, however, youths' certainty about their occupational identity is similar across the 4 Father/Sibling advice patterns, perhaps because some adolescents capitalize on nonfamilial resources to compensate for an unavailable father.

The other interaction effect revealed that, in divorced families, adolescents' expectations for future college graduation success varied by Mother/Sibling advice pattern such that adolescents with a Lower/Lower pattern have the lowest expectations for future educational success. Other work has shown that children from divorced families have lower educational attainment than children in alwaysmarried families (Amato et al., 1995). This difference may be in part due to the economic pressures often experienced by divorced families as a result of a reduction in income (Cherlin, 1992; McLanahan and Booth, 1989), particularly in mother-headed families (Duncan and Hoffman, 1985). Compared to other youth in divorced families, adolescents with a Lower/Lower Mother/Sibling advice pattern may view themselves as the least able and the least hopeful to further their education resulting in lower expectations for college graduation success and resulting in a tendency not to "bother" to seek advice from mothers and siblings. It should be noted that adolescents in always-married and divorced families did not differ in how Parent/Sibling advice patterns predicted their future family expectations, a finding that expands on previous work showing adolescents from always-married 
and divorced families have similar future family expectations (e.g., Coleman and Ganong, 1984).

Although our sample of adolescents in divorced families was relatively small, we believe our sample is adequate in size to explore the associations between advice-seeking patterns and outcomes for three reasons. First, the sample of adolescents from divorced families is larger than what is typically included in other psychological studies of this family context. Second, despite the small group sizes, we still find group differences in the connections between advice patterns and future plans and expectations. Third, our findings are consistent with previous studies of adolescents' parent-child and sibling relationship experiences in divorced families. We do acknowledge, however, that these findings should be seen as descriptive until they are replicated with a larger sample of adolescents in divorced families.

In sum, parents and siblings play an important role in older adolescents' decisions about occupational, educational, and familial plans, and family members' advice-giving roles may differ across always-married and divorced families. The inclusion of siblings, the use of the pattern-analytic approach, and an examination of advice about life plans in both always-married and divorced families were strengths of this study. More insight into patterns of adolescents' advice seeking about future plans could be gained in future studies by incorporating both adolescents' self-report data and parents' and siblings' perceptions. Family members' perspectives on the content of advice given and their role in adolescents' choices about life plans could be explored. In addition, the between-family differences in advice from parents and siblings about life plans evident in this study could be expanded upon in future work by comparing the experiences of adolescents from the same family (i.e., explore within-family differences).

\section{REFERENCES}

Amato, P. R. (1987). Family processes in one-parent, stepparent, and intact families: The child's point of view. J. Marr. Fam. 49: 327-337.

Amato, P. R. (1993). Children's adjustment to divorce: Theories, hypotheses, and empirical support. J. Marr. Fam. 55: 23-38.

Amato, P. R., and Gilbreth, J. G. (1999). Nonresident fathers and children's well-being: A Meta-analysis. J. Marr. Fam. 61: 557-573.

Amato, P. R., Rezac, S. J., and Booth, A. (1995). Helping between parents and young adult offspring: The role of parental marital quality, divorce, and remarriage. J. Marr. Fam. 57: 43-58.

Anderson, E. R., and Rice, A. M. (1992). Sibling relationships during remarriage. Monographs of the Society for Research in Child Development, 57(2/3, Serial No. 227): 149-177.

Barber, B. L. (1994). Support and advice from married and divorced fathers: Linkages to adolescent adjustment. Fam. Rel. 43: 433-438.

Barber, B. L., and Eccles, J. (1992). Long-term influence of divorce and single parenting on adolescent family- and work-related values, behaviors, and aspirations. Psychol. Bull. 111: 106126.

Boer, F., Goedhardt, A. W., and Treffers, P. D. A. (1992). Siblings and their parents. In Boer, F., and Dunn, J. (eds.), Children's Sibling Relationships: Developmental and Clinical Issues. Erlbaum, Hillsdale, NJ, pp. 41-54. 
Brody, G. H., Stoneman, Z., and McCoy, J. K. (1994). Contributions of family relationships and child temperaments to longitudinal variations in sibling relationship quality and sibling relationship styles. J. Fam. Psychol. 3: 274-286.

Brody, G. H., Stoneman, Z., McCoy, J. K., and Forehand, R. (1992). Contemporaneous and longitudinal associations of sibling conflict with family relationship assessments and family discussions about sibling problems. Child Dev. 63: 391-400.

Buhrmester, D. (1992). The developmental course of sibling and peer relationships. In Boer, F., and Dunn, J. (eds.), Children's Sibling Relationships: Developmental and Clinical Issues. Erlbaum, Hillsdale, NJ, pp. 19-40.

Burton, L. M., Allison, K. W., and Obeidallah, D. (1995). Social context and adolescence: Perspectives on development among inner-city African-American teens. In Crockett, L. J., and Crouter, A. C. (eds.), Pathways Through Adolescence: Individual Development in Relation to Social Contexts. Erlbaum, Mahawah, NJ, pp. 119-138.

Cherlin, A. J. (1992). Marriage, Divorce, Remarriage. Harvard University Press, Cambridge, MA.

Cohen, J. (1988). Statistical Power Analysis for the Behavioral Sciences (2nd edn.). Erlbaum, Hillsdale, NJ.

Coleman, M., and Ganong, L. H. (1984). Effect of family structure on family attitudes and expectations. Fam. Relations J. Appl. Fam. Child Stud. 33: 425-432.

Conger, R. D., and Conger, K. J. (1996). Sibling relationships. In Simons, R. L., and Associates (eds.), Understanding Differences Between Divorced and Intact Families: Stress Interaction, and Child Outcome. Sage, Thousand Oaks, CA, pp. 104-124.

Duncan, G. J., and Hoffman, S. D. (1985). Economic consequences of marital instability. In David, M., and Smeeding, T. (eds.), Horizontal Equity, Uncertainty, and Economic Well-being. University of Chicago Press, Chicago, pp. 427-467.

Dunn, J. (1988). Connections between relationships: Implications of research on mothers and siblings. In Hinde, R., and Hinde, J. S. (eds.), Relationships Within Families-Mutual Influences. Oxford University Press, New York, pp. 168-180.

Eccles, J. (1983). Expectancies, values, and academic behaviors. In Spence, J. T. (ed.), Achievement and Achievement Motives. Freeman, San Francisco, CA.

Emery, R. E. (1988). Marriage, Divorce, and Children's Adjustment. Sage, Newbury Park, CA.

Hetherington, E. M. (1988). Parents, children, and siblings six years after divorce. In Hinde, R., and Hinde, J. S. (eds.), Relationships Within Families-Mutual Influences. Oxford University Press, New York, pp. 311-331.

Hines, A. M. (1997). Divorce-related transitions, adolescent development, and the role of the parentchild relationship: A review of the literature. J. Marr. Fam. 59: 375-388.

Hunter, F. T. (1985). Adolescents' perceptions of discussions with parents and friends. Dev. Psychol. 21: $433-440$.

Jenkins, J. (1992). Sibling relationships in disharmonious homes: Potential difficulties and protective effects. In Boer, F., and Dunn, J. (eds.), Children's Sibling Relationships: Developmental and Clinical Issues. Erlbaum, Hillsdale, NJ, pp. 125-138.

Kanoy, K. W., Cunningham, J. L., White, P., and Adams, S. J. (1984). Is family structure that critical? Family relationships of children with divorced and married parents. J. Div. 8: 97-105.

MacKinnon, C. (1989). An observational investigation of sibling interactions in married and divorced families. Dev. Psychol. 25: 36-44.

Magnusson, D. (1988). Individual Development From an Interactional Perspective: A Longitudinal Study. Erlbaum, Hillsdale, NJ.

McHale, S. M., Crouter, A. C., and Bartko, W. T. (1992). Traditional and egalitarian patterns of parental involvement: Antecedents, consequences, and temporal rhythms. In Featherman, D., Lerner, R., and Perlmutter, M. (eds.), Life-Span Development and Behavior (Vol. 11). Erlbaum, Hillsdale, NJ, pp. 49-81.

McLanahan, S. S., and Booth, K. (1989). Mother-only families: Problems, prospects, and politics. J. Marr. Fam. 51: 557-580.

Rogoff, B. (1990). Apprenticeship in Thinking: Cognitive Development in Social Context. Oxford University Press, New York.

Rosnow, R., and Rosenthal, R. (1989). Statistical procedures and the justification of knowledge in psychological science. Am. Psychol. 44: 1276-1284. 
Seginer, R. (1998). Adolescents' perceptions of relationships with older sibling in the context of other close relationships. J. Res. Adolesc. 8: 287-308.

Smollar, J., and Youniss, J. (1985). Parent-adolescent relations in adolecents whose parents are divorced. J. Early Adolesc. 5: 129-144.

Tucker, C. J., Barber, B. L., and Eccles, J. S. (1997). Advice about life plans and personal problems in late adolescent sibling relationships. J. Youth Adolesc. 26: 63-76.

Weiss, R. S. (1979). Growing up a little faster: The experience of growing up in a single-parent household. J. Soc. Issues 35(4): 97-111.

Whiting, B. B. (1983). The genesis of prosocial behavior. In Bridgeman, D. (ed.), The Nature of Prosocial Development: Interdisciplinary Theories and Strategies. Academic Press, London.

Youniss, J., and Smollar, J. (1985). Adolescent relations with mothers, fathers, and friends. Chicago, IL: The University of Chicago Press. 